\title{
A Unified Strategy for the Synthesis of Difluoromethyl- and Vinylfluoride-containing Scaffolds
}

\author{
Nicolas Duchemin, ${ }^{\dagger}$ Roberto Buccafusca, ${ }^{\dagger}$ Marc Daumas,${ }^{\dagger}$ Vincent Ferey, ${ }^{\S}$ and Stellios Arseniyadis ${ }^{\dagger, *}$ \\ 'Queen Mary University of London, School of Biological and Chemical Sciences, Mile End Road, London, E1 4NS (UK) \\ "Sanofi Chimie, Route d'Avignon, 30390, Aramon (France) \\ ${ }^{\S}$ Sanofi R\&D, 371 rue du Professeur Blayac, 34080, Montpellier (France)
}

Supporting Information

ABSTRACT: We report here a general method
for the synthesis of quaternary and tertiary
difluoromethylated compounds and their
vinylfluoride analogues. The strategy, which
relies on a two-step sequence featuring a

Eor several decades now, the introduction of fluorine - atoms and fluorinated groups has drawn the attention of the synthetic organic chemistry community ${ }^{1}$ as these functional groups tend to exhibit enhanced properties compared to their non-fluorinated counterparts; these include greater metabolic stability, lipophilicity, membrane permeability and bioavailability. ${ }^{2,3}$ The difluoromethyl group in particular was shown to exhibit a weak hydrogen bond donating ability and thus act as a bioisostere to carbinols, thiols, amides and hydroxamic acids. ${ }^{4}$ Interestingly, although fluorination and perfluoroalkylation reactions have now reached a certain maturity, the development of an efficient and reliable difluoromethylation reaction to access tertiary difluoromethylated compounds still remains a challenge. Indeed, several limitations such as the choice of the difluoromethylating agent, its regioselectivity, its rather limited substrate scope and the stability of the difluoromethylated products themselves still preclude the use of this reaction as a reliable synthetic tool. ${ }^{6}$ While significant progress has recently been made to access quaternary difluoromethylated compounds through electrophilic $C$-selective difluoromethylation processes by Mikami, $^{7 a}$ Kappe, $^{7 \mathrm{~b}}$ Shen, ${ }^{7 \mathrm{c}}$ Liu, $^{7 \mathrm{~d}}$ Shibata $^{7 \mathrm{e}}$ and $\mathrm{Hu}^{7 \mathrm{f}}$ (Figure 1), examples of methods affording tertiary difluoromethylated derivatives are still rather scarce. In this context, several effective difluoromethylating agents have been recently developed. $\mathrm{Hu}$ and co-workers, for instance, were the first to introduce a tosylsulfoximine based reagent to promote the difluoromethylation of $C$-nucleophiles (I, Figure 1$)^{8}$ while Shibata and co-workers reported the sulfonium and sulfoxinium salts II and III (Figure 1), which both displayed high reactivity albeit moderate $\mathrm{C} / \mathrm{O}$ selectivity. ${ }^{6,9}$ More recently, Shen, ${ }^{7 \mathrm{c}} \mathrm{Liu}^{7 \mathrm{~d}}$ and Shibata $^{7 \mathrm{e}}$ unveiled three new reagents (IV, V and VI, Figure 1) which induced excellent $C$-selectivities in the difluoromethylation of $\beta$-keto esters. These fundamental advances were completed by a recent study

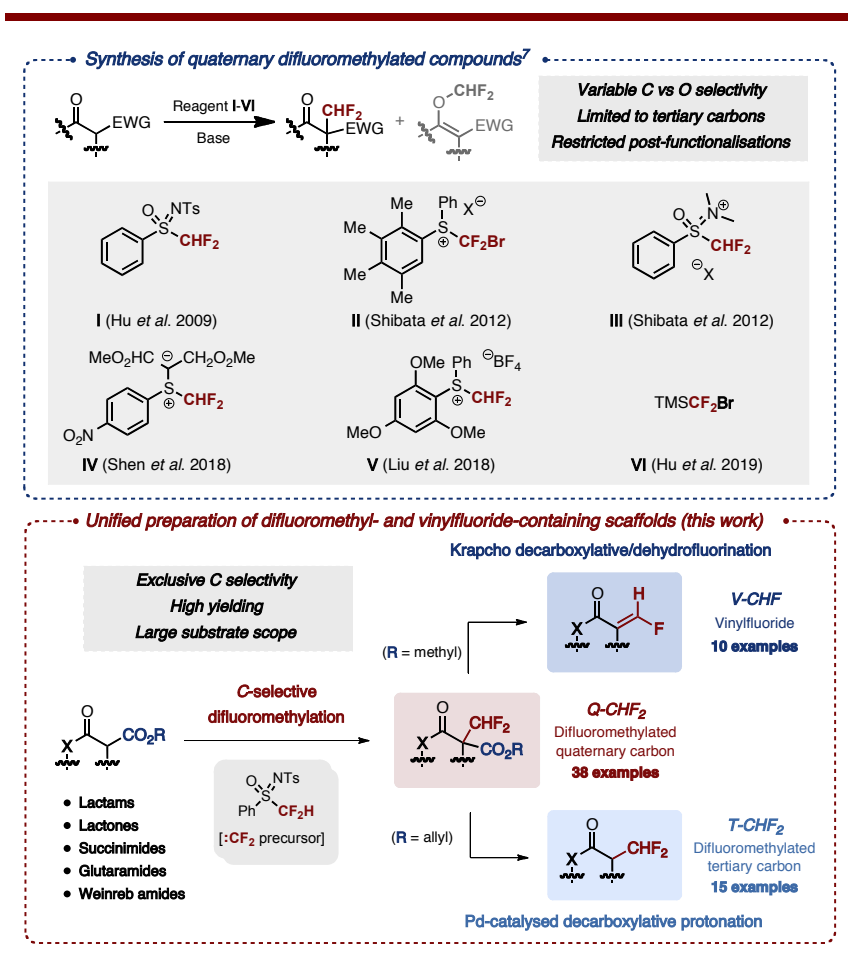

Figure 1. Unified preparation of difluoromethyl and vinylfluoridecontaining scaffolds. 
by $\mathrm{Hu}$ and co-workers who generalized the use of $\mathrm{TMSCF}_{2} \mathrm{Br}$ (VI, Figure 1) to a larger range of $C$-centered nucleophiles. ${ }^{7 \mathrm{f}}$ Surprisingly, while all of these reagents have been used to prepare quaternary difluoromethylated compounds, they all failed to provide the related tertiary derivatives. In this context, we were interested in developing a general method that would allow a straightforward access to a wide range of synthetically and biologically relevant quaternary $\left(Q-C H F_{2}\right)$ and tertiary $\left(T-\mathrm{CHF}_{2}\right) \mathrm{C}$-difluoromethylated scaffolds as well as their vinylfluoride $(\mathrm{V}-\mathrm{CHF})$ analogues. As we will see, the combination of a highly $C$-selective difluoromethylation with either a palladium-catalyzed decarboxylative protonation or a Krapcho decarboxylation/dehydrofluorination enables a practical and scalable route to a variety of fluorinated building blocks (Figure 1). ${ }^{10,11}$ These methods were eventually applied to the late-stage functionalization of various natural products and APIs; we report here the results of our endeavor.

The choice of the difluoromethylating agent was the starting point of our study. Indeed, several criteria needed to be met; ideally the difluoromethylating agent needed to exhibit high regioselectivity while the transient difluoromethylating species needed to be generated in an unbiased and controlled fashion to minimize any undesirable side reaction that could occur during the process. Hu's reagent, $S$-(difluoromethyl)-Sphenyl- $N$-tosylsulfoximine I, appeared as the perfect candidate as the generation of the difluorocarbene was proven to be solely induced by the enolate independently of the base used. ${ }^{8,12}$ Additionally, this solid and bench-stable reagent is easy to use and can be prepared on a multi-gram scale in only three steps starting from thiophenol. ${ }^{13}$

To conduct the optimization of the difluoromethylation step, we chose $N$-Boc-protected $\beta$-methylester valerolactam 1 as a model substrate. Interestingly, a complete $C$-selectivity of the reaction was observed; the desired $C$-difluoromethylated lactam 2a being the only product detected by ${ }^{19} \mathrm{~F}$ and ${ }^{1} \mathrm{H}$ NMR of the crude reaction mixture. A thorough screening of the conditions showed the ineffectiveness of organic bases such as $\mathrm{Et}_{3} \mathrm{~N}$ and DBU (Table 1, entries 1-2) and mild inorganic bases such as $\mathrm{K}_{2} \mathrm{CO}_{3}$ (see SI for a complete base screen). The use of stronger bases such as NaH, LiHMDS or KHMDS led to higher yields (Table 1, entries 3-5), however the best results were obtained with non-nucleophilic alkoxides such as potassium tert-butoxide, which afforded the desired lactam in $66 \%$ yield (Table 1 , entry 6 ).

Both the concentration and the stoichiometry proved to be crucial for the reaction to proceed efficiently with $0.15 \mathrm{M}$ concentration, 2.1 equiv. of base and 2 equiv. of $\mathbf{I}$ being the best conditions (Table 1, entry 8). A drastic loss in reactivity was observed when the "naked" enolate was engaged. Indeed, in the presence of 18-crown- 6 , the yield dropped from $66 \%$ to $10 \%$ although 1 equiv. of $\mathbf{I}$ was consumed (Table 1, entry 9) thus clearly stressing the dual role of the enolate which acts both as a base and as a nucleophile.

A thorough screening of the nature of the solvent showed the superiority of DCM over all the other solvents as the corresponding $C$-difluoromethylated product was obtained in $69 \%$ yield after $6 \mathrm{~h}$ (See SI for a complete solvent screen). This yield could be further improved by simply conducting the reaction at $-40{ }^{\circ} \mathrm{C}(81 \%$, Table 1 , entry 11$)$.

With these optimal conditions in hand, we naturally turned our attention towards the scope of the reaction. As a general trend, no discrepancies were observed when varying either the protecting group on the nitrogen atom, the nature of the ester

\begin{tabular}{cccccc}
\hline Table 1. Systematic study. ${ }^{\mathrm{a}}$ & & & & \\
\hline
\end{tabular}

${ }^{\mathrm{a}}$ All reactions were run on a $0.1 \mathrm{mmol}$ scale during $24 \mathrm{~h}$. I is added after stirring 1 with the base for $30 \mathrm{~min}$. ' $Y$ Yield determined by $1 \mathrm{H}$ NMR using dibromomethane as an internal standard. 'Reaction ran using 2.1 equiv of 18 -crown- $6 .{ }^{\mathrm{d}}$ Reaction completed after $12 \mathrm{~h}$.

or the scale of the reaction (2-5). This prompted us to use the less bulky Bn-protecting group for the rest of the study. Other six-membered ring heterocyclic scaffolds were evaluated such as glutaramides (6), quinolinones (7) and tetrahydropyrimidine-2,4-diones $(\mathbf{8})$; all afforded high yields ranging from $58 \%$ to $96 \%$. Good to excellent reactivities were also observed with the smaller five-membered ring $\gamma$-lactams $(9),{ }^{10 \mathrm{c}}$ succinimides (11) and oxindoles (12), as the corresponding $C$-difluoromethylated products were obtained in good to excellent yields ranging from $74 \%$ to $93 \%$. Replacing the ester by a ketone was not detrimental to either the reactivity or the selectivity as the corresponding $C$-difluoromethylated product 10 was obtained in $74 \%$ yield. The method could also be successfully applied to the seven-membered ring caprolactam 14 and to the four-membered ring $\beta$-lactam 13, however the latter was isolated in only $17 \%$ yield. This was associated to the relative instability of the corresponding enolate intermediate. Finally, butyrolactones also proved to be good candidates as showcased by the moderate to good yields obtained for $\mathbf{1 5}$ and 16. Several attempts to conduct a direct $\alpha$-difluoromethylation on substrates lacking the ester moiety were made, first on the Boc-protected $\delta$-valerolactam itself and then on the Boc-protected $\delta$-valerolactam bearing a phenyl substituent at the $\alpha$-position, however no conversion was observed confirming the importance of the $\beta$-keto ester motif for the difluoromethylation step (see SI for more details).

Keeping in mind our objective to provide a tool for the synthesis of tertiary difluoromethylated scaffolds, we decided to subject our quaternary difluoromethylated methyl ester derivative 3 to the traditional Krapcho decarboxylation conditions (DMSO, $\mathrm{LiCl}, \mathrm{H}_{2} \mathrm{O}$, heating). Unfortunately, instead of the desired decarboxylation product, we isolated the corresponding $E$-vinylfluoride analogue 17 in $92 \%$ yield (Figure 2). This outcome, most likely due to the increased acidity of the tertiary difluoromethylated intermediate which favors the loss of $\mathrm{HF}$ through an $\mathrm{E}_{1} \mathrm{cb}$ process, was actually also observed by Tunemoto and co-workers. ${ }^{16}$ Nonetheless, we decided to take advantage of this reactivity pattern to synthesize various key vinylfluoride derivatives. We rapidly realized that only $15 \mathrm{~min}$ were necessary to achieve full conversion, high yields and exclusive $E$ stereoselectivity. 


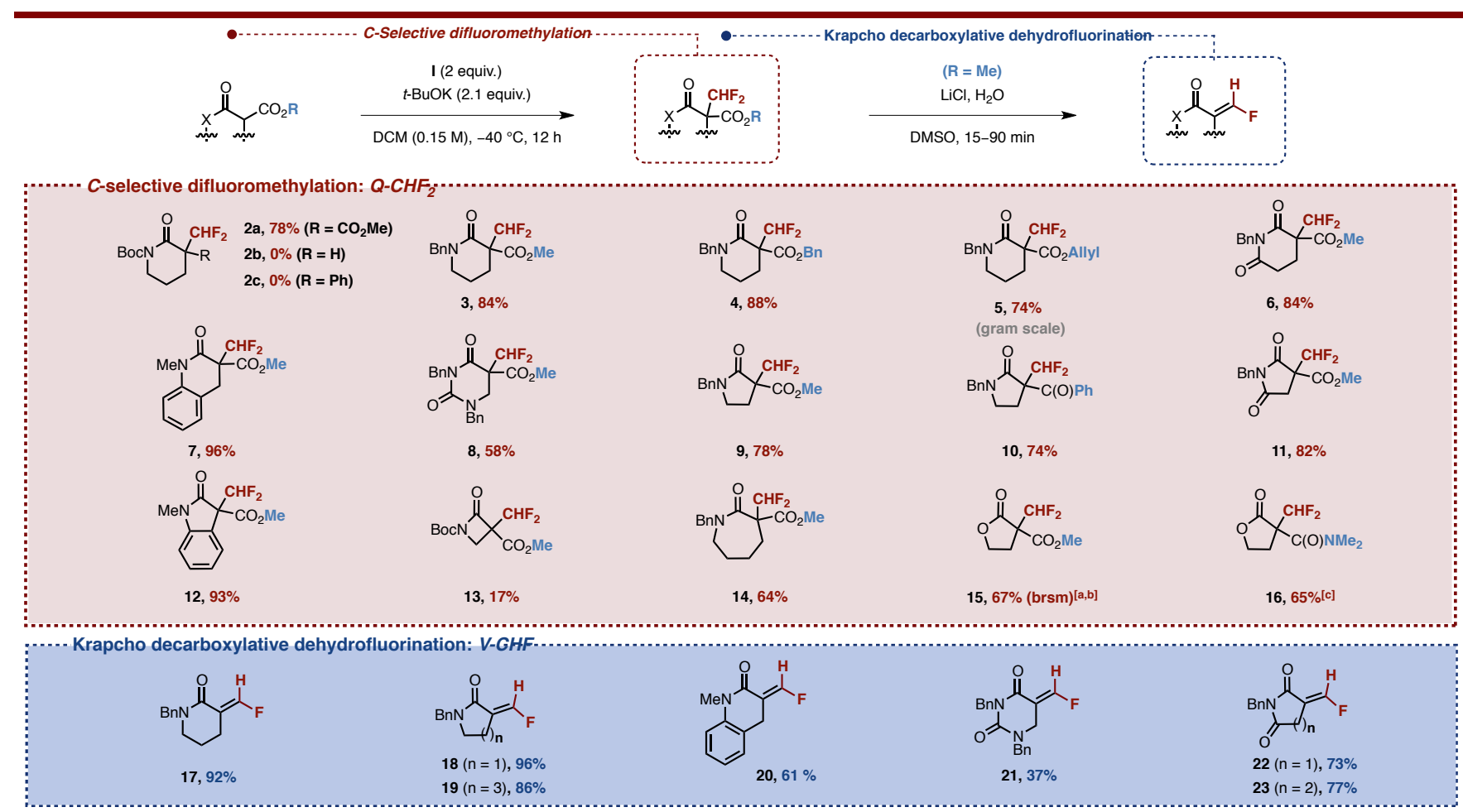

Figure 2. ${ }^{a}$ The reaction was run in THF $(0.1 \mathrm{M})$ at $\mathrm{rt}$ for $3 \mathrm{~d}$. ${ }^{\mathrm{b}}$ Yield based on recovered starting material ( $26 \%$ isolated yield). ${ }^{\mathrm{C}}$ The reaction was allowed to warm up to rt after $12 \mathrm{~h}$ stirring at $-40^{\circ} \mathrm{C}$ and stirring was continued at the same temperature for an additional $36 \mathrm{~h}$.

We believe this selectivity is due to the increased stability of the pro- $E$ enolate intermediate obtained upon decarboxylation and the $\mathrm{E} 1_{\mathrm{CB}}$ type mechanism which forces an anti-elimination (See SI for full discussion). In general, the 5-, 6- and 7 -membered ring lactams and quinolinones were readily converted to the corresponding vinylfluorides in good to excellent yields ranging from $61 \%$ to $96 \%$ (17-20, Figure 2). Slightly milder conditions were used in the case of the tetrahydropyrimidine-2,4-dione, glutaramide and succinimide derivatives due to stability issues, however the yields remained relatively high (21-23, Figure 2). Hence, although the oxindole derivative couldn't be isolated, this metal-free, fast, trivial to set up and entirely diastereoselective sequence showed a relatively wide applicability as showcased by the various exocyclic $(E)$-monofluoroalkene derivatives obtained.

In our effort to develop a viable route to tertiary difluoromethylated compounds ${ }^{17,18}$ and considering our expertise in the field of Pd-AAA, ${ }^{19}$ we next decided to investigate yet another route involving a palladium-catalyzed decarboxylative protonation of substrates bearing an activated allyl ester. ${ }^{20}$ Indeed, if successful, this would not only provide a straightforward access to the tertiary difluoromethylated scaffolds we were aiming for, it would also be the first example of a palladium-catalyzed decarboxylative protonation applied to a difluoromethylated precursor. A second and wider difluoromethylation scope was therefore conducted; the results are depicted in Figure 3.

As expected, the differences between the allyl and the methyl esters in the difluoromethylation step were negligible; all the substrates engaged led to the $C$-difluoromethylated products in high yields ranging from $69 \%$ to $92 \%$ (24-31) with the exception of glutaramide $\mathbf{2 5}$ and butyrolactone $\mathbf{3 1}$ which were obtained in only $26 \%$ and $37 \%$ yield, respectively.

Considering the importance of Weinreb amides in routine organic synthesis, ${ }^{11}$ we decided to apply the method to such compounds. We were pleased to observe that these acyclic scaffolds could also be successfully difluoromethylated in good to excellent yields ranging from $54 \%$ to $97 \%$ (Figure 3, 32-39). The reaction proved to tolerate various substitution patterns at the $\alpha$-position, from simple alkyls to more complex side chains without showing any side reactivity.

Following these results, we next evaluated the palladiumcatalyzed decarboxylative protonation. Luckily, we rapidly managed to obtain the desired decarboxylated products by simply heating the allyl esters in the presence of $\mathrm{Pd}(\mathrm{OAc})_{2}$, dppe and formic acid. ${ }^{21}$ Lactams, glutaramides, succinimides and quinolinones all proved to be good candidates as the corresponding tertiary difluoromethylated compounds were obtained in good to high yields ranging from $59 \%$ to $87 \%$, including the azapirone derivative $\mathbf{4 2} .^{22}$ Most importantly, the reaction could be run on a gram scale without any noticeable loss in efficiency (40, Figure 3 ). The reaction also proved to be applicable to Weinreb amides as showcased by the formation of the corresponding tertiary difluoromethylated products $48-51$ in yields ranging from $26 \%$ to $83 \%$.

The scope culminated with the application of this $C$-selective difluoromethylation to the late-stage functionalization of biologically relevant targets including natural products [matrine $(\mathbf{5 3}, 33 \%)$, sclareolide $(\mathbf{5 4}, 65 \%)$, pyroglutaminol $(\mathbf{5 7}, 44 \%)$ ] and APIs [aniracetam (52, 45\%), phensuximide $(\mathbf{5 5}, \mathbf{6 0 \%})$ ] (Figure 4$)$. In the case of sclareolide, the difluoromethylation also proved to be remarkably stereoselective as the corresponding difluoromethylated product $\mathbf{5 4}$ was obtained as a single diastereomer. The difluoromethylated analogues of aniracetam, matrine and sclareolide were eventually subjected to the Pd-catalyzed decarboxylative protonation conditions and the desired tertiary difluoromethylated products 58, 59 and 60 were all obtained in good yields and an excellent diastereoselectivity in the case of the sesquiterpene lactone. Surprisingly, in the case of 


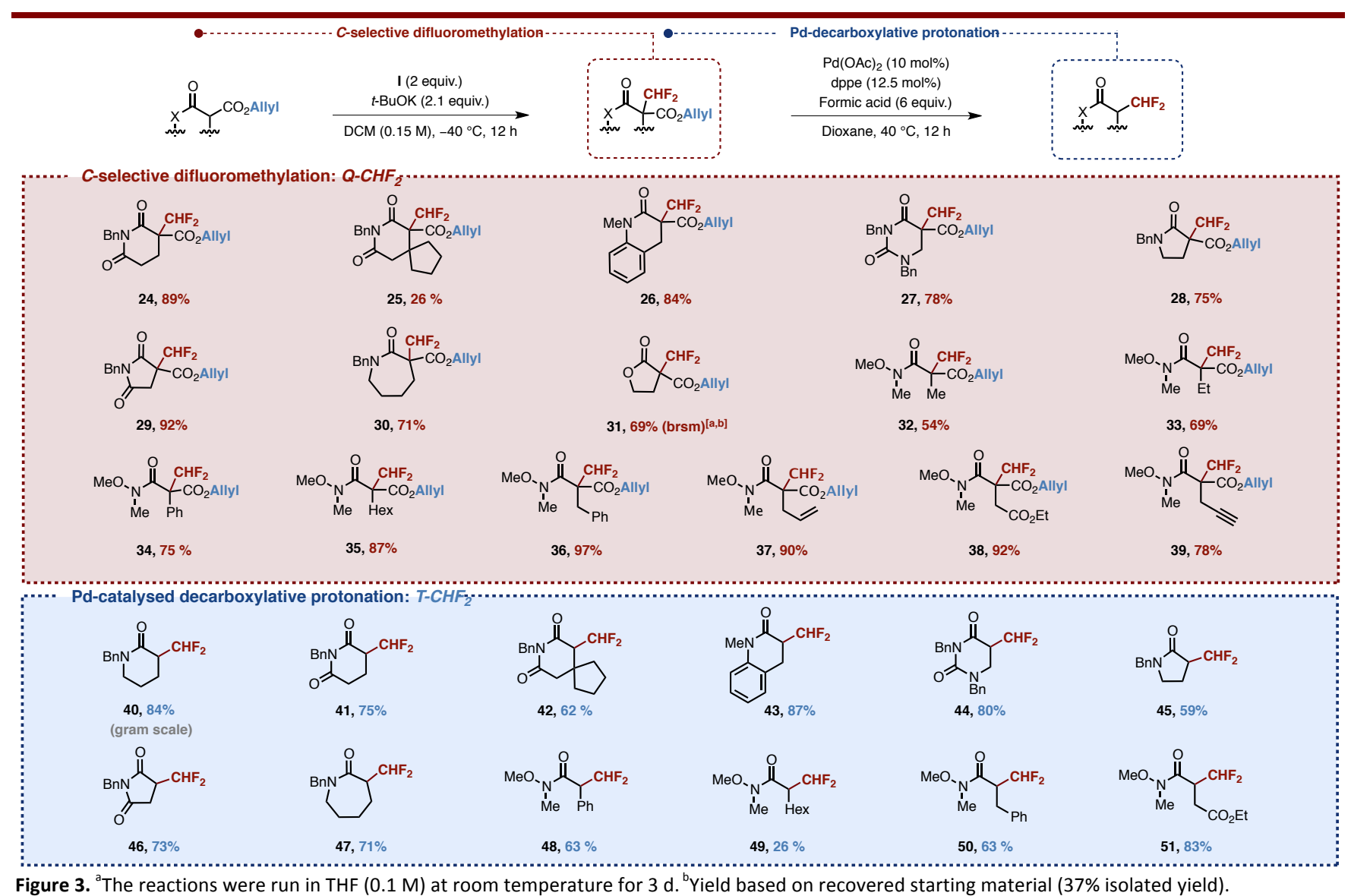

Figure 3. ${ }^{a}$ The reactions were run in THF $(0.1 \mathrm{M})$ at room temperature for $3 \mathrm{~d} .{ }^{b}$ Yield based on recovered starting material $(37 \%$ isolated yield).

compounds 55, 56 and 57, the decarboxylation predominantly led to the vinylfluorides 61, 62 and 63 along with the desired tertiary difluoromethylated products due to the increased acidity of these compounds which favors the $\mathrm{E} 1_{\mathrm{CB}}$ elimination process. To push the reaction towards the complete formation of the vinylfluoride derivatives, the crude reaction mixtures were adsorbed onto silica in the presence of $\mathrm{Et}_{3} \mathrm{~N}$, which allowed to isolate the phensuximide $(61,75 \%)$, costinone $\mathrm{B}^{23}$ $(62,79 \%)$ and pyroglutaminol $(63,79 \%)$ derivatives in overall good yields and with an exclusive (E)-configuration. Interestingly, these last three compounds couldn't be obtained under the Krapcho decarboxylation conditions, which showcases the complementarity between the two methods. Finally, the Yamazaki conditions [LDA, THF, $-78^{\circ} \mathrm{C}$ ], initially developed for the dehydrofluorination of trifluoromethyl moieties, could also be applied (Figure 4, B), ${ }^{24}$ while alternative post-functionalization reactions, including the conversion of valerolactam 3 to the corresponding amide $64\left[\mathrm{NH}_{3}, \mathrm{MeOH}\right.$, reflux, $78 \%$ yield, Figure 4, C] and piperidine $65 \mathrm{LiAlH}_{4}$, THF, reflux, 52\% yield, Figure 4, D] were relatively trivial (See SI for details). This latter result is all the more appealing since piperidines are arguably the most prevalent heterocycle in approved drugs. ${ }^{10 \mathrm{a}}$

In summary, we have developed a highly straightforward, synthesis of both quaternary and tertiary difluoromethylated scaffolds and their $(E)$-vinylfluoride analogues. This strategy, which combines a $C$-selective difluoromethylation with either a palladium-catalyzed decarboxylative protonation or a Krapcho decarboxylation, is practical, usually high yielding and scalable. Moreover, it can be applied to the late-stage functionalization of natural products and APIs, which is particularly useful in the context of drug development.

\section{ASSOCIATED CONTENT}

\section{Supporting Information}

The Supporting information is available free of charge on the Publications website. Details of experimental procedures, ${ }^{1} \mathrm{H}$ and ${ }^{13} \mathrm{C}$ NMR spectra, HPLC chromatograms.

\section{AUTHOR INFORMATION}

\section{Corresponding Author}

*E-mail: s.arseniyadis@qmul.ac.uk

\section{ORCID}

Stellios Arseniyadis: 0000-0001-6831-2631

\section{Notes}

The authors declare no competing financial interest.

\section{ACKNOWLEDGMENT}

Sanofi is gratefully acknowledged for financial support. An early preprint of this work appeared on ChemRxiv (8091314). ${ }^{25}$

\section{REFERENCES}

(1) For selected reviews, see: (a) Liang, T.; Neumann, C. N.; Ritter, T. Angew. Chem. Int. Ed. 2013, 52, 8214-8264; (b) Champagne, P. A.; Desroches, J.; Hamel, J.-D.; Vandamme, M.; Paquin, J.-F. Chem. Rev. 2015, 115, 9073-9174; (c) Barata-Vallejo, S.; Cooke, M. V.; Postigo, A. ACS Catal. 2018, 8, 7287-7307.

(2) (a) Iida, T.; Hashimoto, R.; Aikawa, K.; Ito, S.; Mikami, K Angew. Chem. Int. Ed. 2012, 51, 9535-9538; (b) Purser, S.; Moore, P. R.; Swallow, S.; Gouverneur, V. Chem. Soc. Rev. 2008, 37, 320-330; (c) Wang, J.; Sánchez-Roselló, M.; Luis Aceña, J.; del Pozo, C.; Sorochinsky, A. E.; Fustero, S.; Soloshonok, V. A.; Liu, H. Chem. Rev. 2013, 114, 2432-2506; (d) Gillis, E. P.; Eastman, K. J.; Hill, M. D.; Donnelly, D. J.; Meanwell, N. A. J. Med. Chem. 2015, 58, 8315- 


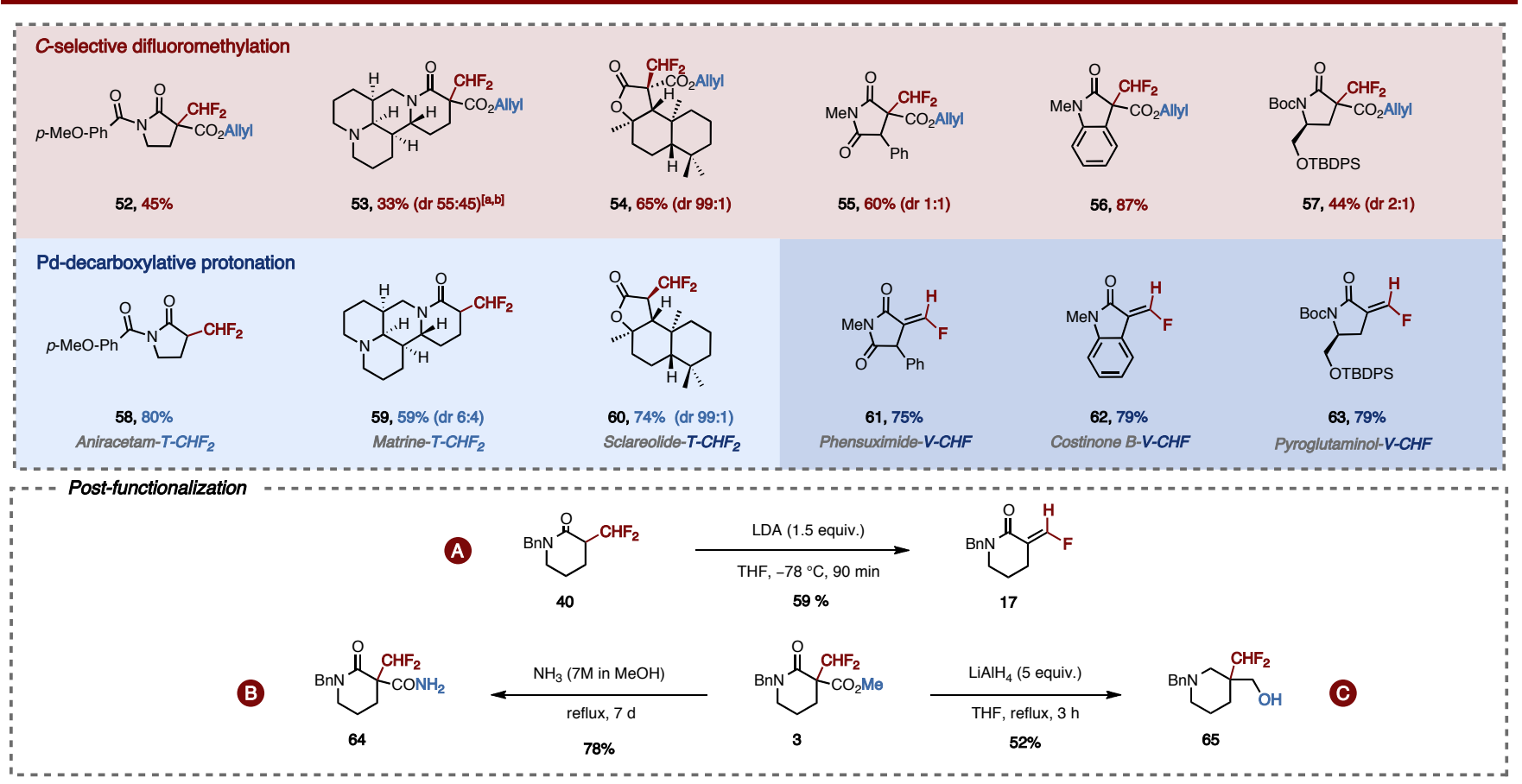

Figure 4. Late-stage functionalization of various natural products and APIs such as aniracetam, matrine, sclareolide, phensuximide, costinone B and pyroglutaminol. ${ }^{\mathrm{a}}$ The reaction was run using 3 equiv. of $\mathrm{I}$ and 3.1 equiv. of $t$-BuOK stirring for $12 \mathrm{~h}$ at $-40{ }^{\circ} \mathrm{C}$ and $72 \mathrm{~h}$ at $40{ }^{\circ} \mathrm{C}$. ${ }^{\mathrm{b}}$ Yield determined by NMR on the crude reaction mixture using an internal standard ( $26 \%$ isolated yield).

8359; (e) Meanwell, N. A. J. Med. Chem. 2018, 61, 5822-5880; (f) Zafrani, Y.; Yeffet, D.; Sod-Moriah, G.; Berliner, A.; Amir, D.; Marciano, D.; Gershonov, E.; Saphier, S. J. Med. Chem. 2017, 60, $797-804$.

(3) There are some exceptions depending on the position of the fluorine atom or the fluorine group within the molecule, see: Müller, K.; Faeh, C.; Diederich, F. Science 2007, 317, 1881-1886.

(4) (a) Sessler, C. D.; Rahm, M.; Becker, S.; Goldberg, J. M.; Wang, F.; Lippard, S. J. J. Am. Chem. Soc. 2017, 139, 9325-9332. (b) Erickson, J. A.; McLoughlin, J. I. J. Org. Chem. 1995, 60, 16261631. (c) Meanwell, N. A. J. Med. Chem. 2011, 54, 2529-2591.

(5) For selected reviews on difluoromethylation, see: (a) Ni, C.; Hu, J. Synthesis 2014, 46, 842-863; (b) Belhomme, M. C.; Besset, T.; Poisson, T.; Pannecoucke, X.; Chem. Eur. J. 2015, 21, 12836-12865; c) Rong, J.; Ni, C.; Hu, J. Asian J. Org. Chem. 2017, 6, 139-152; d) Yerien, D. E.; Barata-Vallejo, S.; Postigo, A. Chem. Eur. J. 2017, 23, 14676-14701.

(6) Yang, Y.-D.; Lu, X.; Liu, G.; Tokunaga, E.; Tsuzuki, S.; Shibata, N. ChemistryOpen, 2012, 1, 221-226.

(7) (a) Iida, T.; Hashimoto, R.; Aikawa, K.; Ito, S.; Mikami, K. Angew. Chem. Int. Ed. 2012, 51, 9535-9538; (b) Köckinger, M.; Ciagla, T.; Bersier, M.; Hanselmann, P.; Gutmann, B.; Kappe, C. O. Green Chem. 2018, 23, 842-845; (c) Zhu, J.; Zheng, H.; Xue, X.-S.; Xiao, Y.; Liu, Y.; Shen, Q. Chin. J. Chem. 2018, 36, 1069-1074; (d) Lu, S.-L.; Li, X.; Qin, W.-B.; Liu, J.-J.; Huang, Y.-Y.; Wong, H. N. C.; Liu, G.-K. Org. Lett. 2018, 20, 6925-6929; (e) Wang, J.; Tokunaga, E.; Shibata, N. Chem. Commun. 2018, 54, 8881-8884; (f) Hu, J.; Xie, Q.; Zhu, Z.; Li, L.; Ni, C. Angew. Chem. Int. Ed. 2019 , doi: 10.1002/anie.201900763.

(8) Zhang, W.; Wang, F.; Hu, J. Org. Lett. 2009, 11, 2109-2112.

(9) Liu, G.; Wang, X.; Lu, X.; Xu, X.-H.; Tokunaga, E.; Shibata, N. ChemistryOpen 2012, 1, 227-231.

(10) (a) Vitaku, E.; Smith, D. T.; Njardarson, J. T. J. Med. Chem. 2014, 57, 10257-10274. (b) Pitts, C. R.; Lectka, T. Chem. Rev. 2014, 114, 7930-7953. (c) Caruano, J.; Muccioli, G. G. Robiette, R. Org. Biomol. Chem. 2016, 14, 10134-10156.

(11) (a) Balasubramaniam, S.; Aidhen, I. S. Synthesis 2008, 23, 3707-3738; (b) Pace, V.; Holzer, W.; Olofsson, B. Adv. Synth. Catal. 2014, 356, 3697-3736.
(12) Pégot, B.; Urban, C.; Bourne, A.; Le, T. N.; Bouvet, S.; Marrot, J.; Diter, P.; Magnier, E. Eur. J. Org. Chem. 2015, 30693075.

(13) Chaabouni, S.; Lohier, J.-F.; Barthelemy, A.-L.; Glachet, T.; Anselmi, E.; Dagousset, G.; Diter, P.; Pégot, B.; Magnier, E.; Reboul, V. Chem. Eur. J. 2018, 24, 17006-17010.

(14) Mayr, H.; Breugst, M.; Ofial, A. R. Angew. Chem. Int. Ed. 2011, 50, 6470-6505.

(15) Trost, B. M.; Schäffner, B.; Osipov, M.; Wilton, D. A. A. Angew. Chem. Int. Ed. 2011, 50, 3548-3551.

(16) Nishide, K.; Kobori, T.; Tunemoto, D.; Kondo, K. Heterocycles 1987, 26, 633-640.

(17) (a) Iseki, K.; Asada, D.; Takahashi, M.; Nagai, T.; Kobayashi, Y. Tetrahedron: Asymmetry 1996, 7, 1205-1215; (b) Tsushima, T.; Kawada, K. Tetrahedron Lett. 1985, 26, 2445-2448.

(18) (a) Amii, H.; Kondo, S.; Uneyama, K. Chem. Commun. 1998 , 1845-1846; (b) Katagiri, T.; Handa, M.; Matsukawa, Y.; Dileep Kumar, J. S.; Uneyama, K. Tetrahedron: Asymmetry 2001, 12, 13031311.

(19) (a) Fournier, J.; Arseniyadis, S.; Cossy, J. Angew. Chem. Int. Ed. 2012, 51, 7562-7566; (b) Fournier, J.; Lozano, O.; Menozzi, C.; Arseniyadis, S.; Cossy, J. Angew. Chem. Int. Ed. 2013, 52, $1257-$ 1261; (c) Arseniyadis, S.; Fournier, J.; Thangavelu, S.; Lozano, O.; Prevost, S.; Archambeau, A.; Menozzi, C.; Cossy, J. Synlett 2013, 2350-2364; (d) Nascimento de Oliveira, M.; Fournier, J.; Arseniyadis, S.; Cossy, J. Org. Lett. 2017, 19, 14-17; (e) Nascimento de Oliveira, M.; Arseniyadis, S.; Cossy, J. Chem. Eur. J. 2018, 24 , 4810-4814; (f) Song, T.; Arseniyadis, S.; Cossy, J. Chem. Eur. J. 2018, 24, 8076-8080; (g) Song, T.; Arseniyadis, S.; Cossy, J. Org. Lett. 2019, 21, 603-607; (h) Aubert, S.; Katsina, T.; Arseniyadis, S. Org. Lett. 2019, 21, 2231-2235.

(20) (a) Tsuji, J.; Nisar, M.; Shimizu, I. J. Org. Chem. 1985, 50, 3416-3417; (b) Kingston, C.; James, J.; Guiry, P. J. J. Org. Chem. 2018, 84, 473-485. (c) Muzar, J. Adv. Synth. Catal. 2019, 361, 1464 1478. (d) Mohr, J. T.; Nishimata, T.; Behenna, D. C.; Stoltz. B. M. J. Am. Chem. Soc. 2006, 128, 11348-11349.

(21) Kingston, C.; Guiry, P. J. J. Org. Chem. 2017, 82, 3806-3819.

(22) The azapirone motif can be found in several approved drugs, see: (a) Eison, A. S. J. Clin. Psychopharmacol. 1990, 10, 2S5S. (b) Cadieux, R. J. Am. Fam. Physician, 1996, 53, 2349-2353. 
(23) Compound $\mathbf{6 2}$ was named after costinone B for the close resemblance of its oxindole scaffold, see: Fatima, I.; Ahmad, I.; Nawaz, S. A.; Malik, A.; Afza, N.; Luttfullah, G.; Choudhary, M. I. Heterocycles, 2006, 68, 1421-1428.
(24) Yamazaki, T.; Ichige, T.; Takei, S.; Kawashita, S.; Kitazume, T.; Kubota, T. Org. Lett. 2001, 3, 2915-2918.

(25) Duchemin, N.; Buccafusca, R.; Daumas, M.; Ferey, V.; Arseniyadis. S. ChemRxiv 2019, 8091314. 